\title{
Selected Time-Lapse Movies of the East Rift Zone Eruption of Kīlauea Volcano, 2004-2008
}

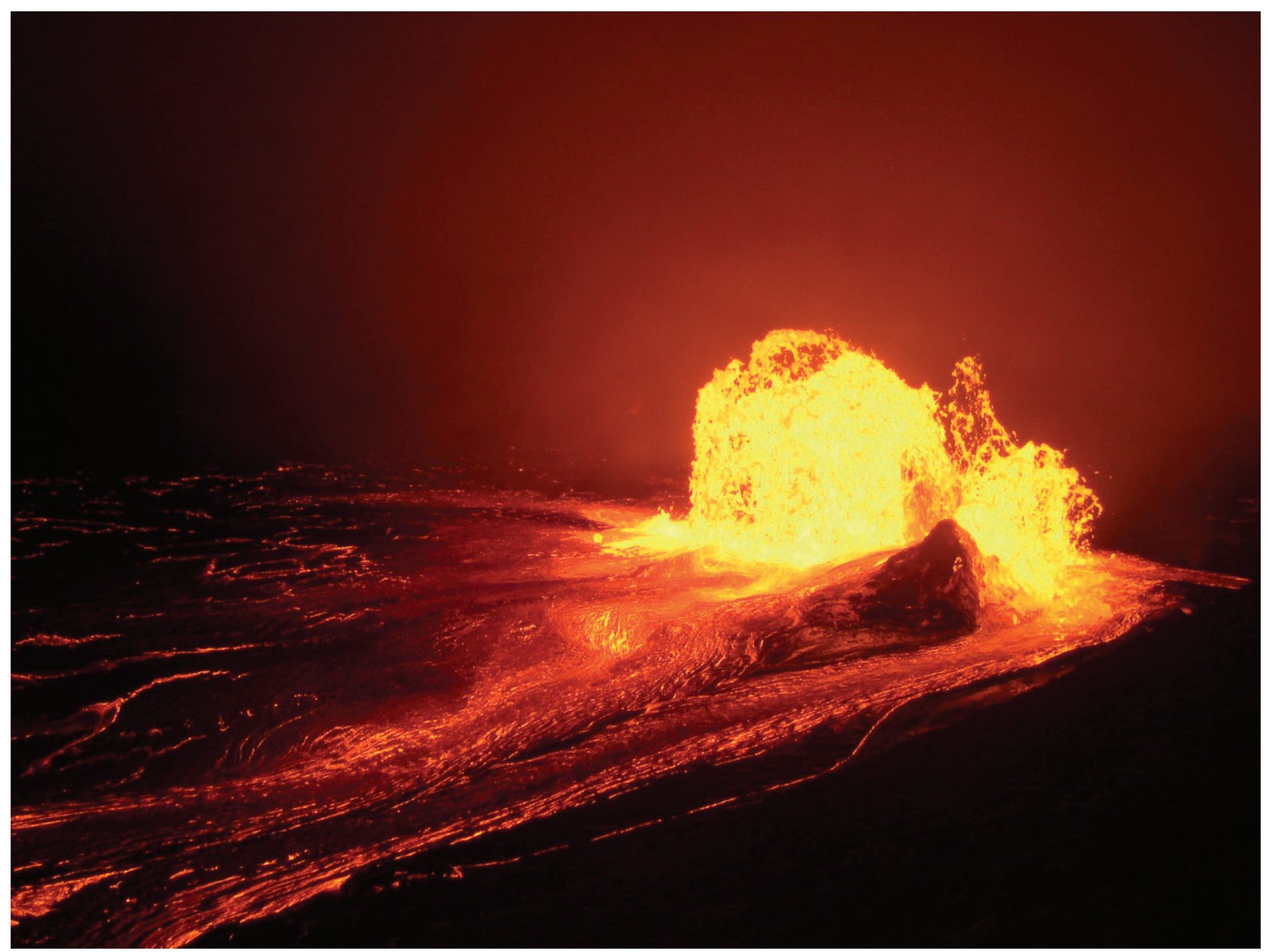

Data Series 621

U.S. Department of the Interior

U.S. Geological Survey 


\section{COVER}

Time-lapse image showing low fountain above the Martin Luther King (MLK) vent feeding a lava flow on the south flank of Pu'u 'Ō‘ō cone in February 2005. 


\section{Selected Time-Lapse Movies of the East Rift Zone Eruption of Kïlauea Volcano, 2004-2008}

By Tim R. Orr

Data Series 621

U.S. Department of the Interior

U.S. Geological Survey 


\section{U.S. Department of the Interior \\ KEN SALAZAR, Secretary}

\section{U.S. Geological Survey Marcia K. McNutt, Director}

\section{U.S. Geological Survey, Reston, Virginia: 2011 \\ For product and ordering information: World Wide Web: http://www.usgs.gov/pubprod Telephone: 1-888-ASK-USGS}

For more information on the USGS - the Federal source for science about the Earth, its natural and living resources, natural hazards, and the environment, visit http://www.usgs.gov or call 1-888-ASK-USGS.

For an overview of USGS information products, including maps, imagery, and publications, visit http://www.usgs.gov/pubprod

To order this and other USGS information products, visit http://store.usgs.gov

Any use of trade, product, or firm names is for descriptive purposes only and does not imply endorsement by the U.S. Government.

Although this report is in the public domain, permission must be secured from the individual copyright owners to reproduce any copyrighted materials contained within this report.

Suggested citation:

Orr, T.R., 2011, Selected time-lapse movies of the east rift zone eruption of Kïlauea Volcano, 2004-2008:

U.S. Geological Survey Data Series 621,15 p., 26 time-lapse movies. 


\section{Contents}

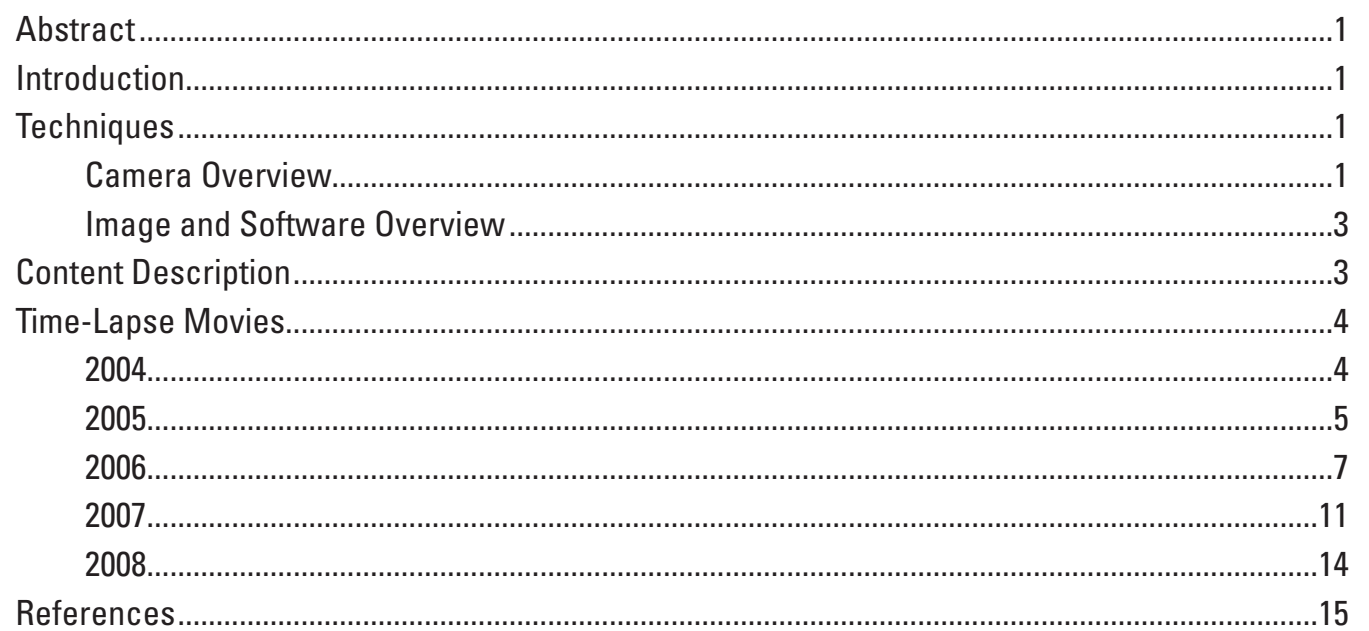

\section{Figures}

Figure 1. Locations of cameras on Kilauea Volcano used to create the time-lapse movies presented in this report. 
This page left blank intentionally. 


\title{
Selected Time-Lapse Movies of the East Rift Zone Eruption of Kīlauea Volcano, 2004-2008
}

\author{
By Tim R. Orr
}

\section{Abstract}

Since 2004, the U.S. Geological Survey's Hawaiian Volcano Observatory has used mass-market digital time-lapse cameras and network-enabled Webcams for visual monitoring and research. The 26 time-lapse movies in this DVD-ROM were selected from the vast collection of images acquired by these camera systems during 2004-2008. Chosen for their content and broad aesthetic appeal, these image sequences document a variety of flow-field and vent processes from Kỉlauea's east rift zone eruption, which began in 1983 and is still (as of 2011) ongoing.

\section{Introduction}

Volcano monitoring and research face several challenges. Important events occur infrequently and are thus seldom witnessed directly by observers. In addition, volcanoes are often inaccessible because of their remote location and (or) harsh environmental conditions. Studying a volcano that is in eruption adds another level of complexity to what may be an already difficult and dangerous situation. For these reasons, the U.S. Geological Survey's (USGS) Hawaiian Volcano Observatory has for decades been using time-lapse camera systems to aid in volcano research and monitoring. As the film-based systems initially used became obsolete, they were replaced by a new generation of digital cameras. The first of these became operative in 1997 and used a video surveillance camera (Thornber, 1997). This was replaced in 2004, as inexpensive, mass-market digital cameras and Webcams (Hoblitt and others, 2008; Orr and Hoblitt, 2008) became widely available. That revolution in technology, aided by the advent of high-speed wireless communications, has greatly expanded the capabilities of visual monitoring at volcanoes worldwide.

Kîlauea's long-lived east rift zone eruption, which began in 1983, was characterized over the first 3.5 years by episodic fountaining and nearby fissure eruptions, which built the $\mathrm{Pu}^{\prime} \mathrm{u}$ ${ }^{`} \bar{O}^{`} \overline{0}$ cinder-and-spatter cone (Episodes 1-48b). In 1986, the eruption shifted $2 \mathrm{~km}$ downrift, where nearly continuous effusion from the Kupaianaha vent built a low shield and emplaced a tube-fed pāhoehoe flow-field (Episode 48c). A brief fissure outbreak between $\mathrm{Pu}^{\prime} u$ ' 'Ō'ō and Kupaianaha in late 1991 (Episode 49) heralded the eruption's move back to $\mathrm{Pu}^{\prime}{ }^{\prime}{ }^{\prime} \overline{\mathrm{O}}^{‘} \bar{o}$ in February 1992. Nearly continuous effusion from vents on the west flank of the $\mathrm{Pu}^{\prime} \mathrm{u}$ ' $\overline{\mathrm{O}}^{`} \bar{o}$ cone over the next 15 years produced more tube-fed flows (Episodes 50-53 and 55). This period of near-continuous effusion was broken by a brief uprift fissure eruption in January 1997 (Episode 54). Heliker and Mattox (2003) present an overview of this early activity.

In 2007, another brief fissure eruption uprift from $\mathrm{Pu}^{\text {' } u}$ ' $\overline{\mathrm{O}}{ }^{‘} \overline{\mathrm{o}}$ (Episode 56; Poland and others, 2008) led to the collapse of the $\mathrm{Pu}^{\prime} \mathrm{u}{ }^{\prime} \overline{\mathrm{O}}^{`} \overline{\mathrm{o}}$ crater floor, followed by a 2-week-long eruptive hiatus. The eruption restarted with the partial refilling of $\mathrm{Pu}^{\prime}{ }^{\prime}{ }^{~ '} \overline{\mathrm{O}}^{‘}$ ō crater (Episode 57; Poland and others, 2008), then shifted downrift again, and lava began erupting from a new vent in between $\mathrm{Pu}^{\prime} \mathrm{u}$ ' $\overline{\mathrm{O}}^{‘} \overline{\mathrm{o}}$ and Kupaianaha (Episode 58; Poland and others, 2008). Over the next 4 years, this new vent-Fissure D - produced tube-fed flows that added to the already vast pāhoehoe flow field that mantles Kîlauea's south flank from rift zone to ocean. Episode 58 ended in March 2011 with another small eruption uprift from $\mathrm{Pu}^{\prime} u$ ' ${ }^{\prime} \mathrm{O}^{‘} \bar{o}$ (Episode 59) that resulted in the collapse of the $\mathrm{Pu}^{c} \mathrm{u}$ ' ${ }^{\prime}{ }^{‘} \overline{\mathrm{o}}$ crater floor. As of this writing (June 2011), activity has resumed at $\mathrm{Pu}^{`} \mathrm{u}{ }^{`} \overline{\mathrm{O}}^{`} \overline{\mathrm{o}}$ (Episode 60) but is confined within $\mathrm{Pu}^{\prime} \mathrm{u}$ ' $\overline{\mathrm{O}}^{‘} \bar{o}^{\prime}$ 's crater.

The time-lapse movies included in this collection represent a variety of volcanic processes and events that occurred during Kīlauea's east rift zone eruption from 2004 to 2008. The movies were selected for their scientific and educational content as well as their aesthetic impact and are intended to appeal to a broad audience. In addition to the movies, which are offered in QuickTime (.mov) format only, the watermarked Joint Photographic Experts Group (.jpg) format images used to compile each movie are also included. The movies and the images are owned by the USGS (Hawaiian Volcano Observatory) and are in the public domain. No permission or fee is required for their use, but photo credit to the U.S. Geological Survey should be included. The images and movies are included "as is" and the U.S. Geological Survey assumes no responsibility for their modification.

\section{Techniques}

\section{Camera Overview}

Two basic camera systems were used to acquire the image sequences presented here-nontelemetered time-lapse 


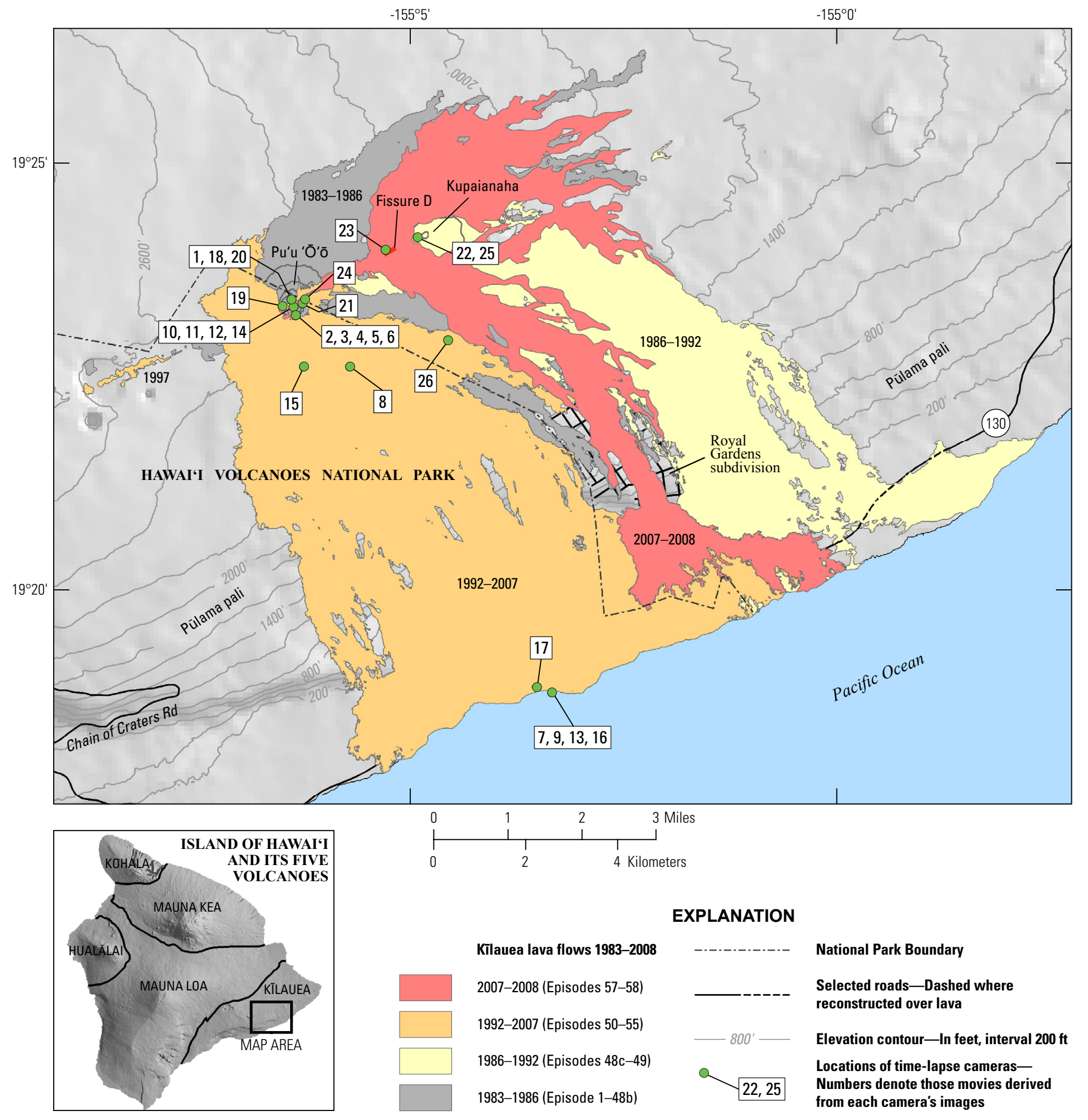

Figure 1. Locations of cameras on Kilauea Volcano used to create the time-lapse movies presented in this report. Also shown is the eruptive flow field for 1983-2008 lavas in Kilauea's east rift zone eruption (begun in 1983 and still ongoing as of 2011). Lavas are divided into four chronological phases, and major vents—Pu'u 'Ō‘ō, Kupaianaha, and Fissure D of Episode 58-are identified. Episode 56 (discussed in text) is not within the area of the map. 
camera systems of the type described by Orr and Hoblitt (2008) and telemetered pan-tilt-zoom Webcams of the type described by Hoblitt and others (2008). Both systems captured JPEG-format images at user-programmed acquisition intervals ranging from about 45 seconds to 10 minutes. The image size of the Webcam images is $640 \times 480$ pixels. The image size recorded by the time-lapse cameras was adjustable, so images acquired by those systems varied from $640 \times 480$ to $1,600 \times$ 1,200 pixels.

The Webcam systems were deployed for long-term monitoring in relatively low-risk environments. Images were acquired wirelessly and archived automatically at the Hawaiian Volcano Observatory. Because these are networked systems, images from the Webcams could also be viewed "live." The time-lapse camera systems, on the other hand, recorded images in the field, and exchange of data memory cards was required to retrieve the acquired images. These systems were designed to be inexpensive, portable, and easy to deploy. As such, the time-lapse camera systems were typically deployed at locations with a higher risk of equipment loss and (or) where wireless telemetry was not possible. Most time-lapse camera deployments were also of short duration (days to weeks), and a handful of cameras survived deployments at dozens of research locations during 2004-2008.

\section{Image and Software Overview}

The movies presented here represent the very best sequences selected from the archive of time-lapse camera and Webcam images. In most cases, the tonal range and color balance of the images were adjusted using image editing software. For some sequences, where the activity of interest was far from the camera, image editing software was used to crop the image to better show the highlighted volcanic process. Image editing software was also used to align and merge adjacent Webcam images, captured seconds apart, to create a sequence of panorama images. The resolution of the images was not down-sampled during any of these process steps.

Image watermarking software was used to add a datetime stamp and the USGS identifier to the images in each image sequence. The size and placement of the date-time stamp and identifier were aesthetically customized for each image sequence. For the time-lapse images, the date-time stamp was taken directly from the EXIF metadata embedded in each image. The camera clock for the time-lapse cameras was reset to local GPS time by hand every month or two, and clock drift was found to be minimal. Thus, the times given by the date-time stamp for the time-lapse camera images are generally good to within a few seconds. For the Webcam images, the date-time watermarks were taken from the image names, which used a date-time naming convention. Image names were assigned programmatically from the computer clock (set to local time by a time server) at the time of acquisition and are good to within a second.

Apple Quicktime Pro Version 7.6.7 was used to assemble the movies from their respective image sequences, and they were saved in .mov format at their native resolution. The movie file size, image acquisition interval, playback speed, and movie duration, along with a detailed description, are listed with each movie below. The latitude, longitude, and approximate viewing azimuth of the camera that acquired the movie are also shown. Clicking on the movie thumbnail opens and begins playing the movie.

\section{Content Description}

This report contains 26 time-lapse movies in Apple Quicktime Movie format (.mov). Each movie is contained within its own descriptively named folder, and the folders are arranged by date. Each movie folder also contains an "images" folder which holds the Joint Photographic Experts Group (JPEG) format (.jpg) images used to create the movie. The JPEG images use a date-time naming convention formatted as YYYYMMDDHHMMSS (year/month/day/hour/ minute/second).

The movies and images are intended to be read across platforms using software capable of opening .jpg and .mov format files. Most Web browsers will open the movies directly if the free Quicktime plug-in is installed, or the movies can be played using the Apple Quicktime Player, available as a free download for both Windows and Mac operating systems. Because the movies are very large files, copying them to your local disk and playing them from there may provide better results. 


\section{Time-Lapse Movies}

\section{4}

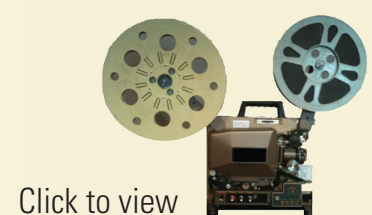

Movie Details:

File size $=88.9 \mathrm{MB}$

Image interval $=\sim 45$ seconds

Playback speed $=15$ frames $/ \mathrm{sec}$

Movie duration $=00: 00: 59$

\section{Camera Coordinates (WGS84):}

Lat: $19.3901^{\circ}$

Long: $-155.1064^{\circ}$

View direction $=\sim 186^{\circ}$
1 - Pu'u ‘'̄‘ō crater lava flow

(March 2, 2004, 11:48:17 to 23:08:42)

Late 2003 through early 2004 marked a period of heightened eruptive activity at $\mathrm{Pu}$ 'u ' $\overline{\mathrm{O}}^{`} \overline{\mathrm{o}}$ (Miklius and others, 2006) on Kīlauea Volcano's east rift zone, with lava frequently spilling from vents within the $\mathrm{Pu}^{\prime} \mathrm{u}{ }^{\prime} \overline{\mathrm{O}}^{‘} \bar{o}$ crater. This time-lapse movie, captured by a Webcam located on the northern rim of $\mathrm{Pu}^{\prime} \mathrm{u}$ ' $\overline{\mathrm{O}}^{`} \overline{\mathrm{o}}$, shows lava erupting from a spatter cone on the southwestern side of the crater floor on March 2, 2004. The vent is about 275 meters from the camera. While most of the erupted lava accumulated below the northern crater wall, as can be seen here, some also poured out of the crater through the West gap - the low area on the right-hand side of the movie - and sent a short lava flow down $\mathrm{Pu}^{\prime} \mathrm{u}$ ' $\overline{\mathrm{O}}^{‘} \overline{\mathrm{o}}$ 's northwestern flank.

The images that make up this movie were captured as a series of three adjacent images spanning the width of the crater with a repeat interval of 1 minute. It took about 20 seconds for the Webcam to acquire the three images. For this movie, only the middle and right-hand images were used. The time stamp shown on each frame is based on the timing of the right-hand image.
Click to view

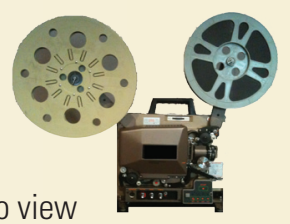

Movie Details:

File size $=141.5 \mathrm{MB}$

Image interval $=\sim 1$ day

Playback speed $=10$ frames $/ \mathrm{sec}$

Movie duration $=00: 01: 05$

\section{Camera Coordinates (WGS84):}

Lat: $19.3870^{\circ}$

Long: $-155.1056^{\circ}$

View direction $=\sim 196^{\circ}$

\section{2 - Long-term change at MLK vent}

(April 2, 2004, to October 28, 2006)

A time-lapse camera was poised on the southwestern flank of $\mathrm{Pu}^{\prime}{ }^{\prime} \mathrm{u}{ }^{\prime} \overline{\mathrm{O}}^{‘} \overline{\mathrm{o}}$ cone from early 2004 through mid-2007. This location overlooked the "Martin Luther King" (MLK) vent, in the foreground ( $\sim 70 \mathrm{~m}$ away), and provided a distant view of the top of the "Prince Kūhiō Kalaniana'ole" (PKK) tube system-the Episode 55 lava tube system that carried lava away from $\mathrm{Pu}^{\prime} \mathrm{u}$ ' ${ }^{\circ}{ }^{‘} \overline{\mathrm{o}}$ during 2004-2007. This movie shows the long-term development of the MLK and PKK vents by compiling one image per day from April 2004 to October 2006. Some days are missing because of poor visibility or equipment failure. In most cases, images have been rotated, shifted, and (or) cropped to account for unavoidable changes in camera position over the deployment period.

The movie highlights the construction and destruction of spatter cones over the MLK and PKK vents, as well as the growth of rootless shields along the upper PKK tube system. It also shows the rapid rise and fall of the ground surface over the MLK vent area, presumably due to pressure changes within an underlying body of magma. 


\section{5}

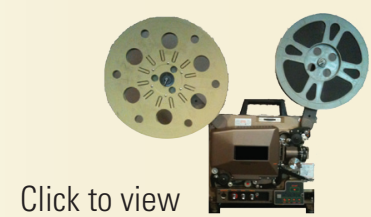

\section{Movie Details:}

File size $=196.5 \mathrm{MB}$

Image interval $=1$ minute

Playback speed $=10$ frames $/ \mathrm{sec}$

Movie duration $=00: 01: 24$

\section{Camera Coordinates (WGS84):}

Lat: $19.3870^{\circ}$

Long: $-155.1056^{\circ}$

View direction $=\sim 196^{\circ}$

\section{3 - Lava fountaining from the MLK vent}

\section{(February 9, 2005, 18:00:30 to February 10, 2005, 08:00:31)}

On February 9, 2005, an increase in lava discharge from $\mathrm{Pu}^{‘} \mathrm{u}{ }^{`} \overline{\mathrm{O}}^{‘} \overline{\mathrm{o}}$, part of a longer term increase in effusion rate (Miklius and others, 2006), resulted in vigorous spattering and low fountaining from the MLK vent. Before the event, the tallest of the small complex of spatter cones over the MLK vent was about 6-7 meters high. This suggests maximum fountain heights of about 10 meters.

The time-lapse camera was positioned on the south flank of the $\mathrm{Pu}^{‘} \mathrm{u}$ ' ${ }^{\prime}{ }^{`} \overline{\mathrm{o}}$ cone, about 70 meters from the erupting cone and about 25 meters upslope from passing lava flows. The prevailing wind direction was from behind the camera, which aided in keeping the camera relatively cool. Simultaneous heightened activity is also visible over the PKK lava tube, indicating that this was a surge through at least the local magmatic system.
Click to view

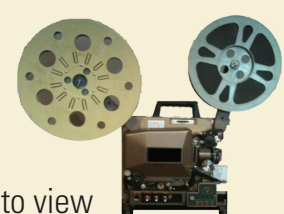

Movie Details:

File size $=46.5 \mathrm{MB}$

Image interval $=1$ minute

Playback speed $=10$ frames $/ \mathrm{sec}$

Movie duration $=00: 00: 12$

Camera Coordinates (WGS84):

Lat: $19.3870^{\circ}$

Long: $-155.1056^{\circ}$

View direction $=\sim 196^{\circ}$

\section{4 - Spatter cone collapse at the MLK vent}

(May 2, 2005, 05:30:04 to 07:30:02)

During spring 2005, activity at the MLK vent, on the southwestern flank of the $\mathrm{Pu}^{\prime} \mathrm{u}{ }^{\prime} \overline{\mathrm{O}}^{`} \bar{o}$ cone, changed from a period of construction to one of destruction. This was highlighted by the collapse of the main MLK spatter cone. The drain-back of lava beneath the spatter cone, following lava extrusion, apparently removed support of the overlying rock. Slight subsidence of the ground surface to the left of the cone can be seen occurring for a few minutes before the cone fell into the resultant cavity, presumably as lava drained away beneath the surface. The extrusion and collapse were also captured by a second timelapse camera on the west side of $\mathrm{Pu}^{\prime} \mathrm{u}{ }^{\prime} \overline{\mathrm{O}}^{‘} \overline{\mathrm{o}}$ (out of sight to the right from this view; see movie 5, below).

The images that make up this movie were acquired by a time-lapse camera positioned on the south flank of the $\mathrm{Pu}^{`} \mathrm{u}$ ' ${ }^{`}{ }^{`} \bar{o}$ cone, about 70 meters from the MLK vent. 
Click to view

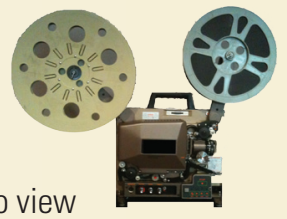

Movie Details:

File size $=32.5 \mathrm{MB}$

Image interval $=1$ minute

Playback speed $=10$ frames $/ \mathrm{sec}$

Movie duration $=00: 00: 26$

\section{Camera Coordinates (WGS84):}

Lat: $19.3870^{\circ}$

Long: $-155.1056^{\circ}$

View direction $=\sim 108^{\circ}$

\section{5 - Spatter cone collapse at the MLK vent} (May 2, 2005, 02:30:28 to 07:30:37)

The spatter cone collapse described above (see movie 4) was also recorded by a time-lapse camera on the west flank of the $\mathrm{Pu}^{\prime} u$ ' ${ }^{`} \overline{\mathrm{o}}^{`} \mathrm{o}$ cone. This camera was located about 70 meters from the MLK vent and recorded two pulses of lava effusion from the vent before collapse. The first, and larger, pulse of effusion was abruptly terminated by a large spatter burst that threw small gobs of spatter at least as far as the time-lapse camera.
Click to view

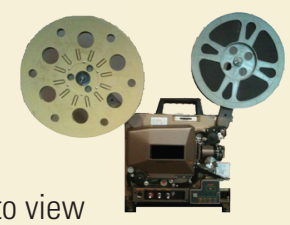

\section{Movie Details:}

File size $=39.9 \mathrm{MB}$

Image interval $=1$ minute

Playback speed $=10$ frames $/ \mathrm{sec}$

Movie duration $=00: 00: 13$

\section{Camera Coordinates (WGS84):}

Lat: $19.3870^{\circ}$

Long: $-155.1056^{\circ}$

View direction $=\sim 196^{\circ}$

\section{Click to view}

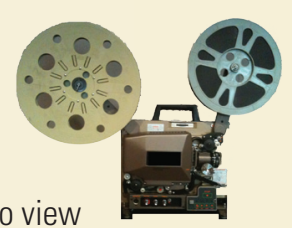

\section{Movie Details:}

File size $=263.6 \mathrm{MB}$

Image interval $=1$ minute

Playback speed $=10$ frames $/ \mathrm{sec}$

Movie duration $=00: 00: 33$

\section{Camera Coordinates (WGS84):}

Lat: $19.3133^{\circ}$

Long: $-155.0555^{\circ}$

View direction $=\sim 248^{\circ}$

\section{6 - Lava pond spattering and overflow at the MLK vent (May 10, 2005, 16:20:29 to 18:30:29)}

After the collapse of the main spatter cone at the MLK vent (see movies 4 and 5, above), a small lava pond was visible within the new pit. At times, the level of the lava pond rose abruptly, overflowing the rim of the pit. This movie is an example of this and shows the lava surface rising suddenly to overflowing, then spattering as the level dropped back down.

The images that make up this movie were acquired by a time-lapse camera positioned on the south flank of the $\mathrm{Pu}^{\prime} u{ }^{\prime}{ }^{\prime} \overline{\mathrm{O}}^{`} \overline{\mathrm{o}}$ cone about 70 meters from the MLK vent.

\section{7 - Lava delta collapse at East Lae'apuki (November 28, 2005, 10:30:05 to 16:00:05)}

At 11:10 in the morning on November 28, 2005, the lava delta at the East Lae 'apuki ocean entry, on Hawai'i's southeastern coast, began to collapse into the ocean. This was not a catastrophic failure of the 13.8-hectare delta, but instead occurred by piecemeal calving of the front of the delta over a period of just less than 5 hours. The collapse removed nearly the entire East Lae'apuki delta and included 4.1 hectares of the older sea cliff inland from the delta. The surface that collapsed was 830 meters long (parallel to the shoreline) and 320 meters wide (perpendicular to the shoreline) and had a total area of 17.8 hectares. Rocks as large as $15 \mathrm{~cm}$ in diameter were blasted as much as 95 meters inland, not uncommon for large delta collapses (Mattox and Mangan, 1997). At the time of the collapse, the ocean entry was being fed by the PKK lava tube which originated on the southwestern flank of $\mathrm{Pu}^{\prime} \mathrm{u}{ }^{'} \overline{\mathrm{O}}^{`} \overline{\mathrm{o}}$.

The images that make up this movie were captured by a time-lapse camera positioned on a small promontory of the older sea cliff on the east side of the East Lae'apuki delta. The spots on the images are water droplets from salt-water spray. 


\section{6}

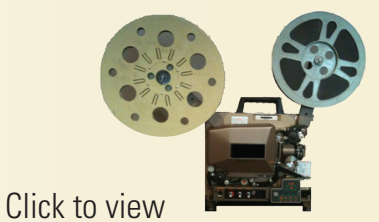

Movie Details:

File size $=6.8 \mathrm{MB}$

Image interval $=10$ minutes

Playback speed $=10$ frames $/ \mathrm{sec}$

Movie duration $=00: 00: 26$

\section{Camera Coordinates (WGS84):}

Lat: $19.3770^{\circ}$

Long: $-155.0950^{\circ}$

View direction $=\sim 270^{\circ}$

\section{8 - Shatter ring on the PKK lava tube}

(March 20, 2006, 11:30:10 to March 22, 2006, 07:00:16)

The flow field feature seen here in profile is a shatter ring. Shatter rings are circular to elliptical volcanic features, typically tens of meters in diameter, that form over active lava tubes (Kauahikaua and others, 2003; Orr, 2011) They are typified by an upraised rim of blocky rubble and a central depression. Dozens of shatter rings have been identified on volcanoes in Hawai' $i$, and they have been reported from basaltic lava fields across the globe. They form when lava pressure in the tube repeatedly exceeds the strength of the overlying rock. Flexing and uplift of the tube roof deposits rubble around the edges of the mobile area.

This movie shows a series of four shatter ring uplift cycles over three days, each cycle accompanied by lava breakouts from the base of the shatter ring. The uplift is obvious during daylight hours, but at night only the associated breakout is visible. The shatter ring shown here was about 40 meters across. The time-lapse camera that acquired the images that make up this movie was positioned about 1 kilometer east of the shatter ring, and the images were cropped to highlight the shatter ring.

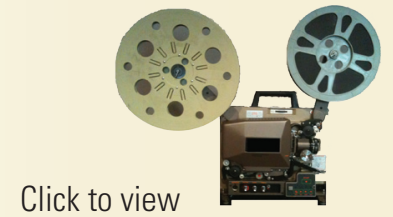

Movie Details:

File size $=34.5 \mathrm{MB}$

Image interval $=1$ minute

Playback speed $=10$ frames $/ \mathrm{sec}$

Movie duration $=00: 00: 53$

\section{Camera Coordinates (WGS84):}

Lat: $19.3133^{\circ}$

Long: $-155.0555^{\circ}$

View direction $=\sim 248^{\circ}$

\section{9 - Lava tube bubble bursts on the East Lae apuki lava delta (May 29, 2006, 10:45:46 to 19:30:49)}

The interaction of sea water and lava creates a volatile situation (Mattox and Mangan, 1997). When this happens inside the confined space of a lava tube, or a narrow, water-filled crack, the results can be impressive. In this movie, lava bubbles, bursting from the top of the PKK lava tube, put on quite a show for several hours. Some of the larger bubble bursts are estimated to have reached heights in excess of 20 meters. The bubble bursts occurred about 350 meters away from the camera. At that distance, a person would be smaller than the watermark characters. As lava flowed away from the site of the bubble bursts, it entered a water-filled crack to the right of center frame, causing additional spattering.

Though the cause of this activity is unknown, the most plausible explanation is that settling of the seaward portion of the delta opened or widened water-bearing cracks that crossed the delta, like that mentioned above. Such cracks would have intersected the lava tube carrying lava to the ocean and allowed seawater to gain direct access to the lava stream.

The images that make up this movie were acquired by a time-lapse camera located on the older sea cliff on the east side of the delta. The images were cropped to highlight the activity. 
Click to view

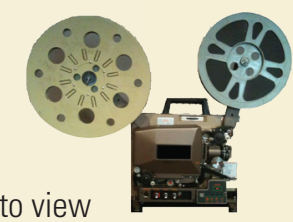

Movie Details:

File size $=96.1 \mathrm{MB}$

Image interval $=1$ minute

Playback speed $=10$ frames $/ \mathrm{sec}$

Movie duration $=00: 00: 45$

\section{Camera Coordinates (WGS84):}

Lat: $19.3886^{\circ}$

Long: $-155.1060^{\circ}$

View direction $=\sim 186^{\circ}$

\section{0 - Gas pistons within the Drainhole vent at Pu 'u ' $\overline{0}$ ‘ō} (June 2, 2006, 18:30:02 to June 3, 2006, 02:00:03)

Gas-pistoning is an interesting phenomenon seen at Kīlauea and some other basaltic volcanoes. It is caused by the accumulation of gas near the top of the lava column within a volcanic vent (Swanson and others, 1979). The shallow accumulation of gas causes the lava surface to rise (the "piston"). Eventually, the gas breaches the surface and escapes, typically as a forceful jet of fume and spatter. The lava then drains back into the vent. Gas pistons can occur as single events or as a repeating series comprising dozens or even hundreds of events. During mid-2006, eruptive activity at the informally named "Drainhole" vent, on the floor of the $\mathrm{Pu}^{\prime} \mathrm{u}{ }^{\prime} \overline{\mathrm{O}}^{\prime} \overline{\mathrm{o}}$ crater, was often characterized by periods of gas-pistoning. This movie sequence is an example of the gas pistons that were occurring at that time.

The images that make up this movie were acquired by a time-lapse camera positioned on the northern rim of the pit that hosted the "Drainhole" vent. The opening in the pit floor is about 5 meters across.
Click to view

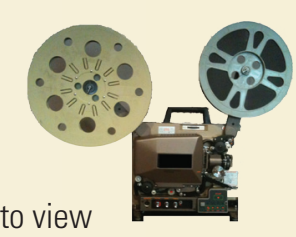

\section{Movie Details:}

File size $=170.7 \mathrm{MB}$

Image interval $=1$ minute

Playback speed $=10$ frames $/ \mathrm{sec}$

Movie duration $=00: 00: 44$

Camera Coordinates (WGS84):

Lat: $19.3886^{\circ}$

Long: $-155.1060^{\circ}$

View direction $=\sim 186^{\circ}$

\section{1 - Gas pistons within the Drainhole vent at $\mathrm{Pu}$ 'u ' $\overline{0} \overline{0}^{\circ}$} (June 3, 2006, 06:00:03 to 13:20:03)

This movie sequence shows another example of gas pistoning (described above in movie 10) captured by the same camera used to compile the previous movie.

\section{Click to view}

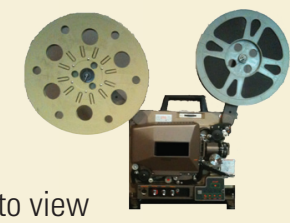

\section{Movie Details:}

File size $=46.9 \mathrm{MB}$

Image interval $=1$ minute

Playback speed $=10$ frames $/ \mathrm{sec}$

Movie duration $=00: 00: 24$

\section{Camera Coordinates (WGS84):}

Lat: $19.3886^{\circ}$

Long: $-155.1060^{\circ}$

View direction $=\sim 186^{\circ}$

\section{2 - Gas pistons within the Drainhole vent at Pu 'u ' $\overline{0}$ ‘ $\overline{0}$}

\section{(June 3, 2006, 21:00:05 to June 4, 2006, 01:00:04)}

This movie sequence is a third example of gas pistoning (described above) captured by the same camera used to compile the previous two movies (10 and 11). 
Click to view

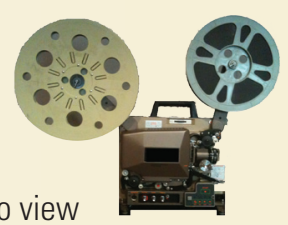

\section{Movie Details:}

File size $=70.8 \mathrm{MB}$

Image interval $=1$ minute

Playback speed $=10$ frames $/ \mathrm{sec}$

Movie duration $=00: 00: 36$

\section{Camera Coordinates (WGS84):}

Lat: $19.3133^{\circ}$

Long: $-155.0555^{\circ}$

View direction $=\sim 248^{\circ}$

\section{3 - Lava breakout from the PKK lava tube at East Lae'apuki}

\section{(June 24, 2006, 19:00:53 to June 25, 2006, 01:00:55)}

After sunset on June 24, 2006, lava burst from the PKK lava tube about 50 meters inland from the older sea cliff bounding the inboard edge of the East Lae'apuki lava delta. Lava reached the sea cliff and began cascading over it in less than a minute, and it spread quickly across the lava delta below. The cascade was mostly crusted over by late afternoon on June 25 , but intermittent surges kept it alive until dawn on June 26, when the event appeared to have finally ended. This movie shows only the initial several hours of the breakout. The sea cliff at the cascade location was about 15 meters high.

The images that make up this movie were acquired by a time-lapse camera positioned on the edge of the older sea cliff at the eastern end of the East Lae'apuki lava delta.
Click to view

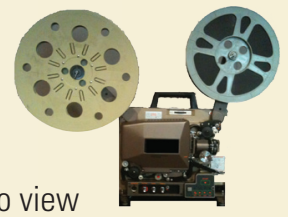

\section{Movie Details:}

File size $=52.5 \mathrm{MB}$

Image interval $=1$ minute

Playback speed $=10$ frames $/ \mathrm{sec}$

Movie duration $=00: 00: 21$

\section{Camera Coordinates (WGS84):}

Lat: $19.3886^{\circ}$

Long: $-155.1060^{\circ}$

View direction $=\sim 90^{\circ}$

\section{4 - Gas pistons within the Drainhole vent at $\mathrm{Pu}$ 'u ' $\overline{\mathrm{O}}$ 'ō} (June 27, 2006, 23:00:23 to June 28, 2006, 02:30:24)

Between June 16 and June 23, 2006, the floor of the pit containing the "Drainhole" vent collapsed, revealing a small lava pond about 12 meters across. Gas pistons (described above) continued to occur but were much larger, as is evident when comparing this movie to those above (movies 10, 11, 12).

The images that make up this movie were acquired by a time-lapse camera positioned on the western rim of the pit that hosted the "Drainhole" vent.
Click to view

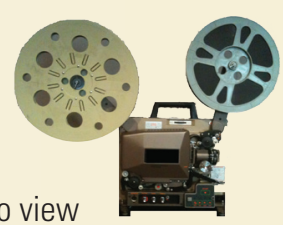

\section{Movie Details:}

File size $=8.3 \mathrm{MB}$

Image interval $=1$ minute

Playback speed $=12$ frames $/ \mathrm{sec}$

Movie duration $=00: 00: 08$

\section{Camera Coordinates (WGS84):}

Lat: $19.3770^{\circ}$

Long: $-155.1040^{\circ}$

View direction $=\sim 254^{\circ}$

\section{5 - Lava stream level rise seen through "Kelly's" skylight (Aug 19, 2006, 00:00:33 to 01:40:33)}

To document changes in the lava stream level within the PKK lava tube, a time-lapse camera was placed at the edge of the informally named "Kelly's" skylight. The camera recorded several abrupt and short-lived increases in lava stream level that eventually sealed the skylight shut. This movie shows a brief increases in lava level of about $1.5 \mathrm{~m}$, which was related to a flux increase through the lava tube (Orr, 2011). 
Click to view

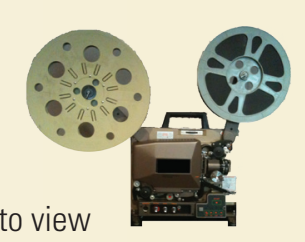

Movie Details:

File size $=71.0 \mathrm{MB}$

Image interval $=1$ minute

Playback speed $=10$ frames $/ \mathrm{sec}$

Movie duration $=00: 00: 36$

\section{Camera Coordinates (WGS84):}

Lat: $19.3133^{\circ}$

Long: $-155.0555^{\circ}$

View direction $=\sim 248^{\circ}$

\section{6 - Lava breakout from the PKK lava tube at East Lae'apuki}

(Sept 21, 2006, 18:00:02 to 00:00:05)

Between the morning of September 20 and the evening of September 22, 2006, there were 10 separate breakouts from the PKK lava tube. Each originated about 50 meters inland from the older sea cliff bounding the inboard edge of the East Lae'apuki lava delta. This movie shows the most spectacular breakout of the series, which fed up to at least twenty separate lava cascades over the 15-meter-high sea cliff. This particular breakout started just after 4 p.m., when glare from the sun was at its worst. Thus, this movie sequence starts at sunset, when the view improves dramatically.

The images that make up this movie were acquired by a time-lapse camera positioned on the edge of the older sea cliff at the eastern end of the East Lae'apuki lava delta.

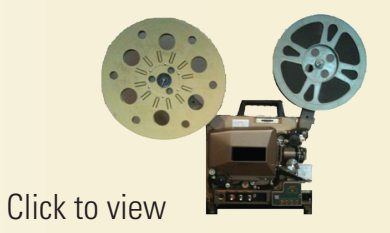

\section{Movie Details:}

File size $=9.9 \mathrm{MB}$

Image interval $=1$ minute Playback speed $=10$ frames $/ \mathrm{sec}$

Movie duration $=00: 00: 10$

\section{Camera Coordinates (WGS84):}

Lat: $19.3144^{\circ}$

Long: $-155.0585^{\circ}$

View direction $=\sim 276^{\circ}$

\section{7 - East Lae'apuki shatter ring}

(October 16 , 2006, 06:20:23 to 08:00:22)

This is another movie showing a shatter ring in action (see movie 8 above for description). This shatter ring, about 55 meters across and 2.5 meters high, grew between late September and mid-October, 2006, as a result of frequent breakouts from the PKK lava tube just inland from the East Lae'apuki lava delta, like the breakout shown in the previous movie. The center of the shatter ring, which becomes visible as the shatter ring uplifts, started out about a meter lower than the lava surface outside the shatter ring. Thus, the center of the shatter ring uplifted about 5 meters during this event. Lava emerges from the base of the shatter ring when the overlying rubble is pushed up and out of the way.

The images that make up this movie were acquired by a time-lapse camera positioned on a tumulus about 75 meters east of the shatter ring. 


\section{7}

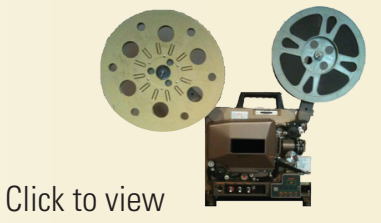

Movie Details:

File size $=5.3 \mathrm{MB}$

Image interval $=1$ day

Playback speed $=6$ frames $/ \mathrm{sec}$

Movie duration $=00: 00: 08$

\section{Camera Coordinates (WGS84):}

Lat: $19.3901^{\circ}$

Long: $-155.1064^{\circ}$

View direction $=\sim 186^{\circ}$

\section{8 - Collapse and refilling of Pu'u ' $\overline{0}$ ‘ $\bar{o}$ crater (June 10 to July 25, 2007)}

During June 17-19, 2007, an intrusion into Kīlauea's upper east rift zone (Episode 56) led to the cessation of eruptive activity at $\mathrm{Pu}^{\prime} \mathrm{u}$ ' ${ }^{\prime} \overline{\mathrm{O}}^{\prime} \overline{\mathrm{o}}$ and the collapse of the $\mathrm{Pu}^{\prime} u$ ' ${ }^{\prime} \overline{\mathrm{C}}^{\prime} \overline{\mathrm{o}}$ crater floor (Poland and others, 2008). The quiet did not last long, though, and lava began to erupt on the floor of the $\mathrm{Pu}^{\prime} \mathrm{u}{ }^{\prime} \mathrm{C}^{\prime}{ }^{\prime} \mathrm{o}$ crater in early July (Episode 57). After several days of slow filling, the crater began to uplift as pressure increased below. Then, just after midnight on July 21, 2007, a new fissure eruption (Episode 58) broke out on the eastern flank of the $\mathrm{Pu}^{\text {' }} \mathrm{u}$ 'Ō'o cone (Poland and others, 2008) and $\mathrm{Pu}^{\prime} \mathrm{u}$ ' $\overline{\mathrm{O}}^{\prime} \mathrm{o}$ 's crater floor collapsed again. This movie shows these events by compiling one image per day for the period June 10 to July 25 .

The images that make up this movie were acquired by a pan-tilt-zoom Webcam positioned on the north rim of the $\mathrm{Pu}^{\prime} \mathrm{u}$ ' $\overline{\mathrm{O}}^{`} \overline{\mathrm{o}}$ crater. The Webcam captured a series of three adjacent images spanning the width of the crater with a repeat interval of 1 minute. For this movie, a single set of three images, acquired roughly at midday and with good visibility, was selected from each day for the period June 10 to July 25 .
Click to view

19 - Lava lake draining event during Pu‘u ‘Ō‘ō refilling (July 5, 2007, 23:00:06 to July 6, 2007, 09:00:06)

With the resumption of eruptive activity at $\mathrm{Pu}^{\prime} \mathrm{u}^{\prime}{ }^{\mathrm{O}}{ }^{‘} \mathrm{o}$ on July 1, 2007 (Episode 57), a lava lake, fed by two vents, quickly began to form within the $\mathrm{Pu}^{6} \mathrm{u}$ ' $\bar{O}^{`} \bar{o}$ crater. The vent seen here was located on the eastern side of the crater. The other vent, out of sight to the left, was located on the west-central part of the crater floor. Several times during the early part of the refilling process, lava stopped erupting and the lava lake partly drained back into the vent. Moments later, lava re-emerged as the eruption resumed. This movie shows one of these draining events, followed by a smaller secondary draining, during the night of July 5-6, 2007.

The images that make up this movie were acquired by a time-lapse camera

\section{Camera Coordinates (WGS84):}

Lat: $19.3887^{\circ}$

Long: $-155.1082^{\circ}$

View direction $=\sim 91^{\circ}$ positioned on the northwest edge of the $\mathrm{Pu}^{\prime} \mathrm{u}{ }^{\prime} \overline{\mathrm{O}}^{`} \overline{\mathrm{o}}$ crater, about 190 meters from the erupting vent. The camera was later lost when the crater floor and a portion of the crater rim collapsed following the onset of Episode 58 on July $21,2007$. 
Click to view

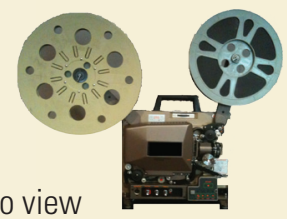

\section{Movie Details:}

File size $=39.4 \mathrm{MB}$

Image interval $=1$ minute

Playback speed $=15$ frames $/ \mathrm{sec}$

Movie duration $=00: 00: 24$

\section{Camera Coordinates (WGS84):}

Lat: $19.3901^{\circ}$

Long: $-155.1064^{\circ}$

View direction $=\sim 186^{\circ}$

\section{0 - Refilling of Pu‘u ‘Ō‘ō crater}

(July 8, 2007, 05:00:14 to 12:00:12)

The refilling of $\mathrm{Pu}^{\prime} \mathrm{u}$ ' $\overline{\mathrm{O}}^{`} \overline{\mathrm{o}}$ during Episode 57 was driven by the eruption of lava from two vents - one on the west-central part of the crater floor (to the right) and the other on the eastern side of the crater (to the left). This movie shows the competing interaction between flows from these two vents for a period of several hours on July 8 .

The images that make up this movie were acquired by a pan-tilt-zoom Webcam positioned on the north rim of the $\mathrm{Pu}^{\prime} \mathrm{u}{ }^{\prime} \overline{\mathrm{O}}^{‘} \bar{o}$ crater. The Webcam captured a series of three adjacent images spanning the width of the crater with a repeat interval of 1 minute. It took about 20 seconds for the Webcam to acquire the three images. The time-stamp shown on each frame is based on the timing of the right-hand image.
Click to view

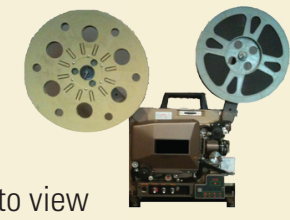

\section{Movie Details:}

File size $=25.3 \mathrm{MB}$

Image interval $=1$ minute

Playback speed $=15$ frames $/ \mathrm{sec}$

Movie duration $=00: 00: 28$

\section{Camera Coordinates (WGS84):}

Lat: $19.3893^{\circ}$

Long: $-155.1042^{\circ}$

View direction $=\sim 303^{\circ}$

\section{1 - Refilling of Pu'u 'Ō‘ō crater \\ (July 13, 2007, 14:00:30 to 21:00:36)}

As stated above (movies 19 and 20), Episode 57 was driven by the eruption of lava from two vents - one on the west-central part of the crater floor and the other on the eastern side of the crater. This movie shows lava erupting from the eastern of the two vents. Lava can be seen occasionally overtopping levees that formed along the edges of the lava lake.

The images that make up this movie were acquired by a time-lapse camera positioned on the southeastern rim of the $\mathrm{Pu}^{\prime} \mathrm{u}^{\prime} \overline{\mathrm{O}}^{‘} \overline{\mathrm{o}}$ crater, about $125 \mathrm{~m}$ from the erupting vent.
Click to view

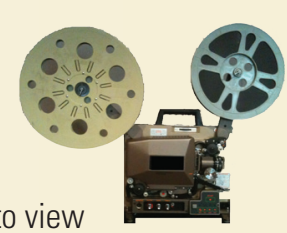

\section{Movie Details:}

File size $=18.8 \mathrm{MB}$

Image interval $=\sim 1$ day

Playback speed $=10$ frames $/ \mathrm{sec}$

Movie duration $=00: 00: 08$

\section{Camera Coordinates (WGS84):}

Lat: $19.4022^{\circ}$

Long: $-155.0818^{\circ}$

View direction $=\sim 263^{\circ}$

\section{2 - Long-term evolution of the Episode 58 lava channel (September 8 to November 30, 2007)}

Within days of the onset of Episode 58 on July 21, 2008, activity localized on the easternmost eruptive fissure-Fissure D (see figure 1) - and channelized lava began flowing to the northeast. Repeated overflows from the channel added slowly to its height, and the channel became perched up to 45 meters above the pre-existing lava surface.

The images that make up this movie were captured by a time-lapse camera positioned on the west flank of the Kupaianaha lava shield, about 500 meters from the channel. The erupting vent over Fissure $\mathrm{D}$ is the fume source near the left side of the view, and $\mathrm{Pu}^{\prime} \mathrm{u}$ ' $\overline{\mathrm{O}}^{`} \overline{\mathrm{o}}$ is the cone in the background behind that. The channel flow direction is from left to right. 


\section{3 - Dome fountain over Fissure D vent of the Episode 58 eruption (September 20, 2007, 05:00:03 to 09:00:03)}

Click to view

As the Episode 58 lava channel developed, the upper end of the channel crusted over so that lava - extruding from the erupting fissure - flowed through a short tube before entering the channel. A small surge of lava on September 20, 2007, exceeded the carrying capacity of this tube and resulted in a small dome

Movie Details:

File size $=19.3 \mathrm{MB}$

Image interval $=2$ minutes

Playback speed $=10$ frames $/ \mathrm{sec}$

Movie duration $=00: 00: 12$

Camera Coordinates (WGS84):

Lat: $19.3998^{\circ}$

Long: $-155.0880^{\circ}$

View direction $=\sim 64^{\circ}$ fountain through the tube roof near the head of the lava channel. Fortunately, the fountain was short-lived and quit before the cliff on which the camera stood was overtopped by lava.

The images that make up this movie were acquired by a time-lapse camera positioned on a small cliff about 70 meters west of the dome fountain. The trace of Fissure D runs directly beneath the camera. Lava enters the channel to the right and flows toward the left.
Click to view

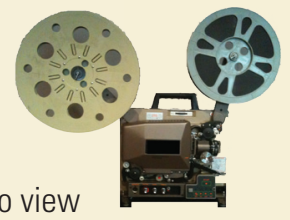

\section{Movie Details:}

File size $=61.7 \mathrm{MB}$

Image interval $=1$ minute

Playback speed $=10$ frames/sec

Movie duration $=00: 00: 24$

\section{Camera Coordinates (WGS84):}

Lat: $19.3901^{\circ}$

Long: $-155.1037^{\circ}$

View direction $=\sim 55^{\circ}$

\section{4 - Episodic spattering in the Episode 58 lava channel}

(November 15, 2007, 09:00:15 to 13:00:15)

Periods of overflow and levee construction at the Episode 58 lava channel were interspersed with periods when the lava level was below the channel rim. The lava surface within the lava channel commonly experienced repeated cycles of rise and fall, as shown here. During these cycles, the lava surface would rise slowly, then spattering would abruptly commence along the edge of the lava stream, and the lava surface would drop rapidly. This behavior is equivalent to that of gas pistoning, as described above (movies 10-12, 14), and suggests that the process is driven by gas accumulation beneath the crust of the lava stream.

The images that make up this movie were acquired by a time-lapse camera positioned just below the eastern rim of $\mathrm{Pu}^{\prime} u$ ' $\overline{\mathrm{O}}^{`} \overline{\mathrm{o}}$, about 2.2 kilometers west of the perched channel. The images were cropped to highlight the activity within the channel. 


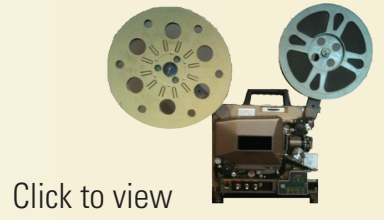

\section{Movie Details:}

File size $=96.1 \mathrm{MB}$

Image interval $=2$ minutes

Playback speed $=10$ frames $/ \mathrm{sec}$

Movie duration $=00: 00: 42$

\section{Camera Coordinates (WGS84):}

Lat: $19.4022^{\circ}$

Long: $-155.0818^{\circ}$

View direction $=\sim 226^{\circ}$

\section{5 - TEB effusion and partial rootless shield flank failure}

(December 1, 2007, 02:01:38 to 16:01:36)

On November 21, 2007— the eve of the U.S. Thanksgiving holiday-Episode 58 changed dramatically. Lava, erupting from Fissure D into a perched lava channel, found an easier path to the surface and broke out from directly over Fissure D on what was, by then, the southern flank of the channel. This switch in the eruption led to the eventual demise of the Episode 58 perched lava channel in early 2008.

The "Thanksgiving Eve breakout" (TEB) lava flow spread to the south from Fissure D and quickly began to build a string of rootless shields. The rapid accumulation of lava to form shields did not allow flows to completely cool before being buried by subsequent flows. This resulted in the storage of molten or semi-molten lava within and on the flanks of the rootless shields. At times, this accumulated lava could not be contained and was released suddenly, producing rapidly moving ' $a$ 'a flows, as can be seen in this movie. Lava, accumulating on the east flank of a rootless shield below the TEB vent, is suddenly released, carrying huge chunks of cooled and coherent lava as it moves to the left. The steep walls that had surrounded the ponded lava come into view as the lava drains toward the southeast.

The images that make up this movie were acquired by a time-lapse camera positioned on the west flank of Kupaianaha, about 300 meters away from the nearest flows.

\section{8}

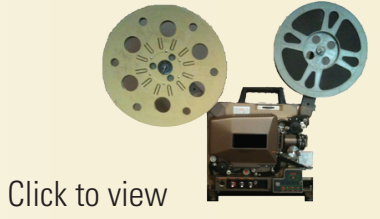

\section{Movie Details:}

File size $=73.7 \mathrm{MB}$

Image interval $=1$ minute

Playback speed $=10$ frames $/ \mathrm{sec}$

Movie duration $=00: 00: 50$

\section{Camera Coordinates (WGS84):}

Lat: $19.3821^{\circ}$

Long: $-155.0758^{\circ}$

View direction $=\sim 3^{\circ}$

\section{6 - TEB rootless shield flank failure}

(January 26, 2008, 10:50:12 to 19:12:16)

Perched lava ponds often formed atop the rootless shields built by the "Thanksgiving Eve Breakout" (TEB) lava flow. This movie shows the failure of the flank of a rootless shield on January 26, 2008, and the release of the lava contained within the perched lava pond at its summit. The inner wall of the perched lava pond come into view as the lava drains out to feed a channelized 'a'a flow advancing to the southeast (to the right). The terminus of this flow entered the upper part of the mostly-abandoned Royal Gardens subdivision before stagnating.

The images that make up this movie were acquired by a time-lapse camera positioned about 1 kilometer south of a steep-sided rootless shield topped by a lava pond. 


\section{References}

Heliker C., and Mattox T.N., 2003, The first two decades of the $\mathrm{Pu}^{\prime} \mathrm{u}$ ' ${ }^{\prime}{ }^{‘} \overline{\mathrm{o}}-\mathrm{Kupaianaha}$ eruption; chronology and selected bibliography, in Heliker C., Swanson D.A., and Takahashi T.J., eds., The $\mathrm{Pu}^{\prime} \mathrm{u}{ }^{\prime} \overline{\mathrm{O}}^{`} \overline{\mathrm{o}}-$ Kupaianaha eruption of Kîlauea Volcano, Hawai' $i$; the first 20 years: U.S. Geological Survey Professional Paper 1676, p. 1-27.

Hoblitt, R.P., Orr, T.R., Castella, F., and Cervelli, P.F., 2008, Remote-controlled pan, tilt, zoom cameras at Kīlauea and Mauna Loa volcanoes, Hawai' ${ }^{\prime}$ i: U.S. Geological Survey Scientific Investigations Report 2008-5129, 14 p.

Kauahikaua, J., Sherrod, D.R., Cashman, K.V., Heliker, C., Hon, K., Mattox, T.N., and Johnson, J.A., 2003, Hawaiian lava-flow dynamics during the $\mathrm{Pu}^{\prime} \mathrm{u}$ ' ${ }^{\circ}{ }^{`} \bar{o}-$ Kupaianaha eruption; a tale of two decades, in Heliker C., Swanson D.A., and Takahashi T.J., eds., The $\mathrm{Pu}^{\prime} \mathrm{u}$ ' ${ }^{\circ}{ }^{`} \overline{\mathrm{o}}-\mathrm{Kupaianaha}$ eruption of Kîlauea Volcano, Hawai' $i$; the first 20 years: U.S. Geological Survey Professional Paper 1676, p. 63-87.

Mattox, T.N., and Mangan, M.T., 1997, Littoral hydrovolcanic explosions; a case study of lava-seawater interaction at Kîlauea Volcano: Journal of Volcanology and Geothermal Research, v. 75, no. 1-2, p. 1-17.
Miklius, A., Poland, M., Desmarais, E., Sutton, A., Orr, T., and Okubo, P., 2006, Recent Inflation of Kilauea Volcano [abs.]: Eos (American Geophysical Union Transactions), v. 87, Fall meeting supplement, abs. G43C-01.

Orr, T.R., 2011, Lava tube shatter rings and their correlation with lava flux increases at Kîlauea Volcano, Hawai' $i$ : Bulletin of Volcanology, v. 73, p. 335-346.

Orr, T.R., and Hoblitt, R.P., 2008, A versatile time-lapse camera system developed by the Hawaiian Volcano Observatory for use at Kīlauea Volcano, Hawai'i: U.S. Geological Survey Scientific Investigations Report 2008-5117, 8 p.

Poland, M., Miklius, A., Orr, T., Sutton, J., Thornber, C., and Wilson, D., 2008, New episodes of volcanism at Kîlauea Volcano, Hawai'i: Eos, (American Geophysical Union Transactions), v. 89 , no. 5 , p. 37-38.

Swanson, D.A., Duffield, W.A., Jackson, D.B., and Peterson, D.W., 1979, Chronological narrative of the 1969-71 Mauna Ulu eruption of Kilauea volcano, Hawai'i: U.S. Geological Survey Professional Paper 1056, 55 p.

Thornber, C.R., 1997, HVO/RVTS-1; a prototype remote video telemetry system for monitoring the Kilauea east rift zone eruption, 1997: U.S. Geological Survey Open-File Report 97-537, $18 \mathrm{p}$. 
这

옥

훟

罗

꼴

余

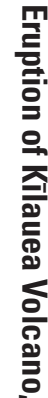

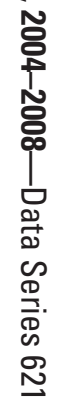

